\title{
The Librarian's Internet Survival Guide: Strategies for the High-Tech Reference Desk. Irene E. McDermott. Edited by Barbara Quint. Medford, N.J.: Information Today Inc., 2002. 265 pages. ISBN 157387129X.
}

Irene E. McDermott, author of The Librarian's Internet Survival Guide, is a reference librarian and systems manager at the San Marino Public Library in California. She writes the monthly column "Internet Express" in Searcher magazine. This book is a collection of McDermott's columns about useful Web sites and includes advice on a broad range of topics related to the Internet.

The book's simple layout and design makes it easy to read. This publication has an extensive index at the end, and it is divided into two parts. The first part deals with ready reference on the Web. The first chapter explores search and meta-search engines and is followed by chapters on how to find people and news on the Internet. Chapter four is devoted to the use of portals and subject directories. There is also a chapter on sites for children and another on how to find free full-text resources. Chapter seven lists resources for medical and health information online. The last two chapters in the first part focus on managing your finances and cybershopping. The second part of the book is more technical in nature and offers practical information on topics such as managing Web-based e-mail, teaching the Internet, maintaining Web pages, troubleshooting computers, etc. The last chapter in the book is about how to keep up with the continuously changing World Wide Web.

I found the book an interesting read. Most sections list Web sites accompanied by a brief description, but there are also sections on safety issues, evaluating content and credibility of Web sites, privacy, etc. McDermott personalizes the descriptions and writes with ease. She often uses real-life examples and humour. Each chapter starts with a lively introduction. I definitely enjoyed the chapter on teaching users how to search the Internet, especially the section on capturing the "beginner mind".

Unfortunately, most of the content focuses on American sites. There is only one Canadian site mentioned (in the chapter on minding your money), and it is a site about information on Canadian companies. I found it disturbing that most of the sites are commercial (.com), followed by educational (.edu) and government (.gov) sites. Included are also a few UK sites and one site from each of the following countries: Germany, Mexico, Sweden, and the Netherlands.

For health sciences librarians, the second part of the book may prove more useful than the first, especially the chapter on making the Internet more accessible to the disabled and the chapter on troubleshooting computers. I am often asked by patients or visitors of the hospital to assist with Web e-mail on a daily basis. Rebooting "frozen" computers, clearing cache, and unjamming printers is a regular routine.

In conclusion, depending on the type of questions and the customer base, the book may be more or less relevant to different types of libraries. It is intended mostly for public librarians, but it could be useful to school and academic librarians or lay users. Library students working on projects may also find the book interesting. I would not recommend it to health sciences libraries, since I have seen other publications explicitly targeting health-related Internet resources.

\section{Penka Stoyanova}

Health Sciences Librarian

Credit Valley Hospital

Mississauga, ON L5M 2N1

E-mail: pstoyanova@cvh.on.ca 